\title{
SUPPLEMENTAL RESULTS
}

\section{Full length AMPA receptor and truncated TMD simulation setup}
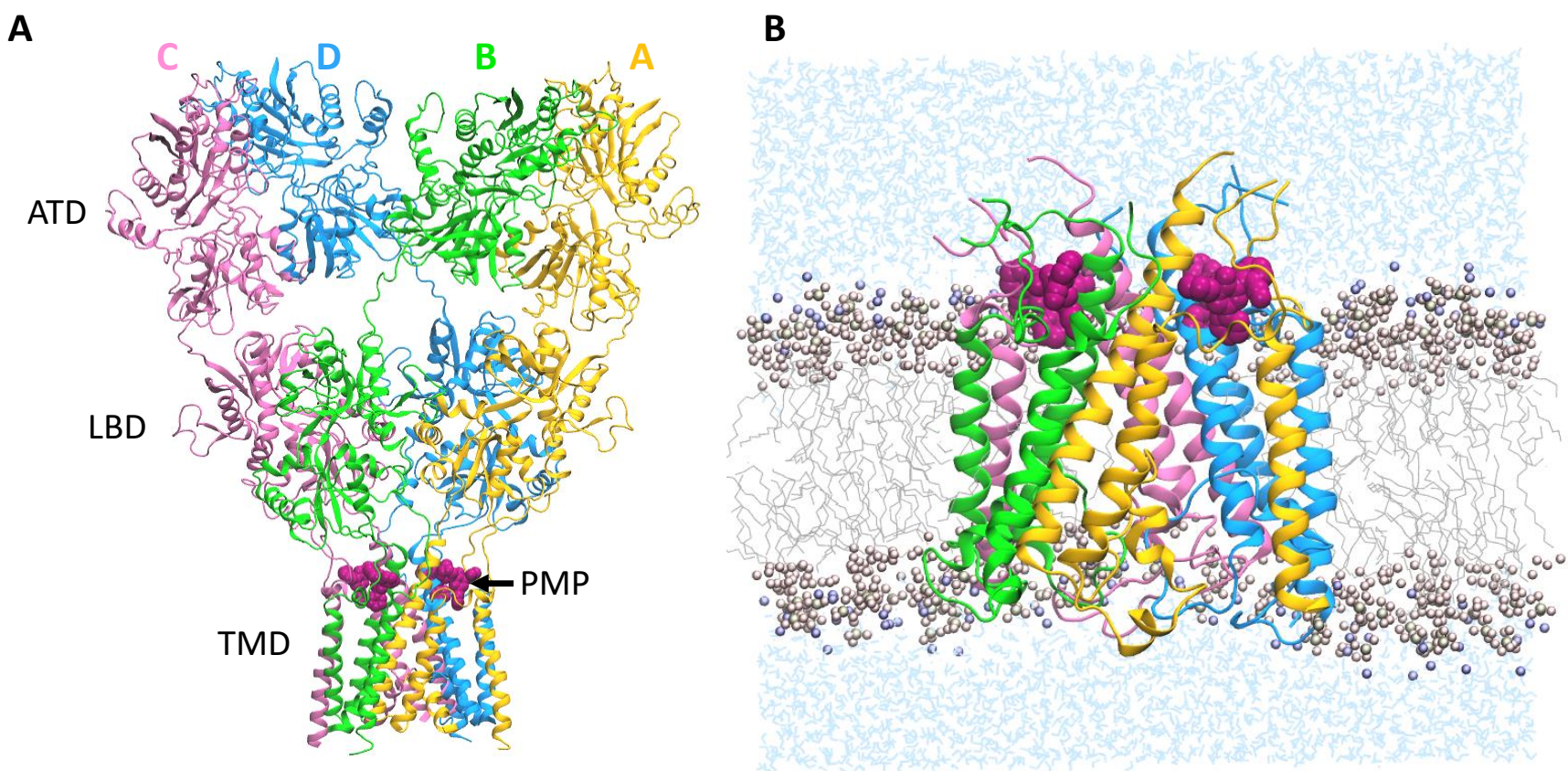

Figure S1. A) Full length AMPA receptor in complex with PMP (PDB: 5L1F.) Different subunits are colored in different colors. B) A simulated truncated complex. Simulated AMPAR-PMP complex in POPC lipid membrane and water is shown. Starting structure was PDB: 5L1F. Only TMD and S1M1/S2-M4 linkers were simulated. Protein subunits are shown in different colors in cartoon representation. The four bound PMP inhibitors are shown in magenta space-filled representation. Some lipids and waters are removed for clarity 


\section{Ligand RMSD and binding site RMSD from TMD-LBD simulation}
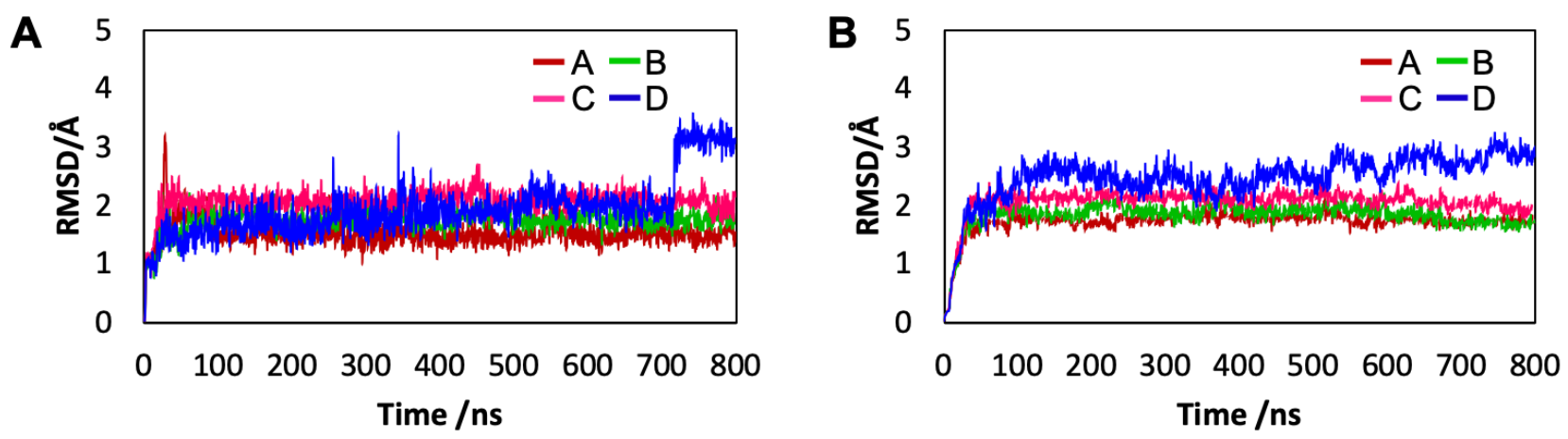

Figure S2: A) Ligand "RMSD" of PMP in bindings sites A, B, C, and D based on selected ligandprotein residue distances with respect to initial ligand position. B) RMSD of the binding site in subunits A, B, C, and D - residues 511-523 (pre-M1/S1-M1 linker), 615-629 (M3), and 786-795 (M4/S2-M4 linker) - with respect to initial structure.

\section{Supplementary docking and MD simulation results}

\section{Interactions of PMP with the binding site}

Results of PMP simulations are summarized in Table S1. A majority of initial contacts in PMP crystal poses are maintained throughout the simulations. These include contacts with K511, S516, F517, D519, P520, F623, and N791 in all four crystal poses and Y616 in three out of the four poses (PMPB loses this contact). All four crystal poses lose contact with residues L518 and S788 and form new contacts with L787 and S615 of the adjacent subunit. All crystal poses except PMPD also form a new contact with P513. PMPA and PMPC gain contacts with S510 and L620, which are present initially in PMPB and PMPD. Additionally, P512 and V792 remain in contact with three and two simulated poses respectively. A hydrogen bond between the nitrile group of PMP and side chain OH of S516 is present in all X-ray crystal poses with the exception of PMPC (see Table S1). However, this hydrogen bond is quickly lost during MD simulations and new ones are formed. In simulated crystal poses, carboxyl oxygen of PMP participates in a hydrogen bond with either the side chain $\mathrm{OH}$ group of S510 (PMPB/D), or backbone NH group of K511 (PMPA/C) (Table S1 and Figure S3). These hydrogen bonds are formed by displacing a water molecule that acts as a hydrogen bond acceptor in the absence of the ligand. Nitrile group of PMP forms a weaker hydrogen bond with the backbone nitrogen of G513 in two of the simulated poses (PMPA/B). Carbonyl and nitrile groups of PMP are also the main groups that participate in hydrogen bonding in docked poses. The most stable hydrogen bond formed by a majority of poses that docked with a different orientation from that of the crystal structure is between the carbonyl group of PMP and the side chain amide group of N791. This hydrogen bond is maintained in both PMP1A and PMP1C, the docked poses with the lowest TI binding free energies. Residues K511, G513, N791, V792 (backbone nitrogens) 
and S510 (side chain OH group) are other residues that participate in hydrogen bonding with docked poses. Pyridinyl ring nitrogen of docked poses PMP1B and PMP1D form weak hydrogen bonds with residues N791 and V792 respectively. The binding site residues L620, F623, N791, S516, D519, P520, S615(adjacent subunit), F517, Y616 and K511 remain in contact with PMP in all poses. Residues S510, P512, L787, G513, L624, V792, N619, and S785 of the neighboring subunit form close contacts with PMP in some binding poses. 


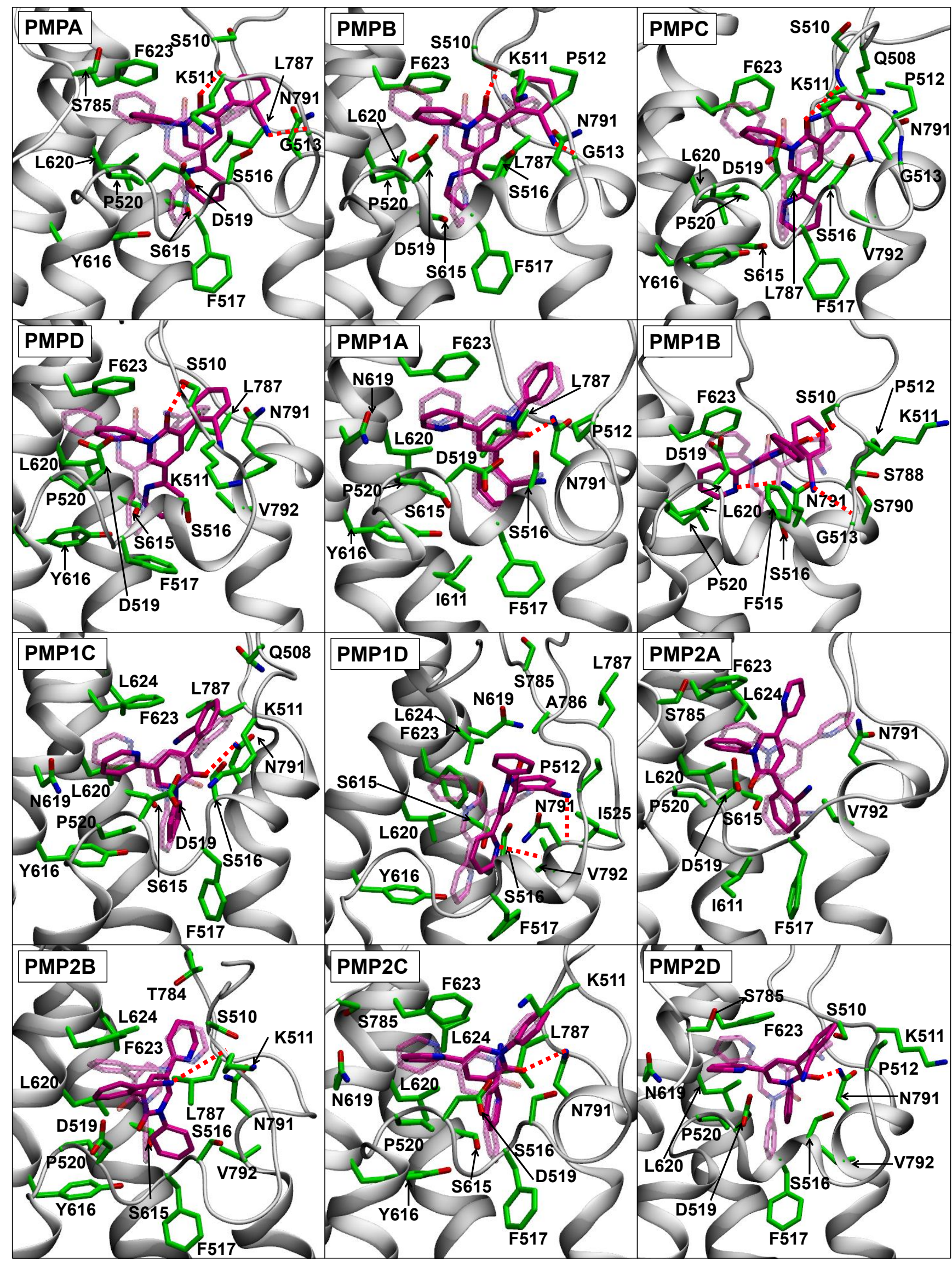


Figure S3. Binding poses of PMP. Simulated representative structure (opaque) is superimposed on initial ligand position (transparent). All residues within $4 \AA$ of the ligand in the simulated structure are shown. Hydrogen bonds are shown in red dotted lines.

\begin{tabular}{|c|c|c|c|c|c|c|}
\hline $\begin{array}{l}\text { Binding } \\
\text { pose }\end{array}$ & $\begin{array}{l}\text { Orientation } \\
\text { (group) }\end{array}$ & $\begin{array}{l}\text { Average } \\
\text { ligand } \\
\text { RMSD/ } \\
\AA\end{array}$ & $\begin{array}{l}\text { Initial H- } \\
\text { bonds }\end{array}$ & $\begin{array}{l}\mathrm{H} \text {-bonds in } \\
\text { simulated pose }\end{array}$ & Initial contacts & $\begin{array}{l}\text { Contacts in } \\
\text { simulated pose }\end{array}$ \\
\hline PMPA & 1 & 1.78 & $\begin{array}{l}\text { N01- } \\
\text { S516:OG }\end{array}$ & $\begin{array}{l}\text { O11-K511:N, } \\
\text { N01-G513:N, }\end{array}$ & $\begin{array}{l}\text { K511, P512, S516, } \\
\text { F517, L518, D519, } \\
\text { P520, Y616, F623, } \\
\text { S788, N791, } \\
\text { S785(B) }\end{array}$ & $\begin{array}{l}\text { S510, K511, G513, } \\
\text { S516, F517, D519, } \\
\text { P520, Y616, L620, } \\
\text { F623, L787, N791, } \\
\text { S785(B), S615(D) }\end{array}$ \\
\hline PMPB & 1 & 2.46 & $\begin{array}{l}\text { N01- } \\
\text { S516:OG }\end{array}$ & $\begin{array}{l}\text { O11-S510:OG, } \\
\text { N01-G513:N, }\end{array}$ & $\begin{array}{l}\text { S510, K511, S516, } \\
\text { F517, L518, D519, } \\
\text { P520, Y616, L620, } \\
\text { F623, S788, N791 }\end{array}$ & $\begin{array}{l}\text { S510, K511, P512, } \\
\text { G513, S516, F517, } \\
\text { D519, P520, L620, } \\
\text { F623, L787, N791, } \\
\text { S615(A) }\end{array}$ \\
\hline PMPC & 1 & 1.99 & No H-bonds & O11-K511:N & $\begin{array}{l}\text { K511, S516, F517, } \\
\text { L518, D519, P520, } \\
\text { Y616, F623, S788, } \\
\text { N791 }\end{array}$ & $\begin{array}{l}\text { Q508, S510, K511, } \\
\text { P512, G513, S516, } \\
\text { F517, D519, P520, } \\
\text { Y616, L620, F623, } \\
\text { L787, N791, V792, } \\
\text { S615(B) }\end{array}$ \\
\hline PMPD & 1 & 2.95 & $\begin{array}{l}\text { N01- } \\
\text { S516:OG }\end{array}$ & O11-S510:OG & $\begin{array}{l}\text { S510, K511, P512, } \\
\text { S516, F517, L518, } \\
\text { D519, P520, Y616, } \\
\text { N619, L620, F623, } \\
\text { S788, N791 }\end{array}$ & $\begin{array}{l}\text { S510, K511, P512, } \\
\text { S516, F517, D519, } \\
\text { P520, Y616, L620, } \\
\text { F623, L787, N791, } \\
\text { V792, S615(C) }\end{array}$ \\
\hline PMP1A & 2 & 1.15 & $\begin{array}{l}\text { N01- } \\
\text { N791:ND2 }\end{array}$ & O11-N791:ND2 & $\begin{array}{l}\text { S510, K511, P512, } \\
\text { G513, S516, F517, } \\
\text { D519, P520, Y616, } \\
\text { N619, L620, F623, } \\
\text { N791, S785(B), } \\
\text { I611(D), S615(D) }\end{array}$ & $\begin{array}{l}\text { P512, S516, F517, } \\
\text { D519, P520, Y616, } \\
\text { N619, L620, F623, } \\
\text { L787, N791, I611(D), } \\
\text { S615(D) }\end{array}$ \\
\hline PMP1B & 1 & 2.22 & $\begin{array}{l}\text { N01- } \\
\text { N791:ND2 }\end{array}$ & $\begin{array}{l}\text { O11-S510:OG, } \\
\text { N01-G513:N, }\end{array}$ & $\begin{array}{l}\text { S510, K511, P512, } \\
\text { G513, S516, F517, } \\
\text { L518, D519, P520, }\end{array}$ & $\begin{array}{l}\text { S510, K511, P512, } \\
\text { G513, F515, S516, } \\
\text { D519, P520, L620, }\end{array}$ \\
\hline
\end{tabular}




\begin{tabular}{|c|c|c|c|c|c|c|}
\hline & & & & $\begin{array}{l}\text { N15- } \\
\text { N791:ND2* }\end{array}$ & $\begin{array}{l}\text { Y616, L620, F623, } \\
\text { S788, S790, N791 }\end{array}$ & $\begin{array}{l}\text { F623, S788, S790, } \\
\text { N791 }\end{array}$ \\
\hline PMP1C & 3 & 1.53 & No H-bonds & O11-N791:ND2 & $\begin{array}{l}\text { S510, K511, S516, } \\
\text { F517, L518, D519, } \\
\text { P520, Y616, N619, } \\
\text { L620, F623, N791, } \\
\text { S785(D) }\end{array}$ & $\begin{array}{l}\text { Q508, K511, G513, } \\
\text { S516, F517, D519, } \\
\text { P520, Y616, N619, } \\
\text { L620, F623, L624, } \\
\text { L787, N791, S615(B) }\end{array}$ \\
\hline PMP1D & 1 & 4.15 & $\begin{array}{l}\text { N01- } \\
\text { N791:ND2 }\end{array}$ & $\begin{array}{l}\text { N01-N791:N*, } \\
\text { N15-V792:N* }\end{array}$ & $\begin{array}{l}\text { S516, F517, L518, } \\
\text { D519, P520, } \\
\text { TRP526, Y616, } \\
\text { L620, F623, L624, } \\
\text { L787, S788, N791 }\end{array}$ & $\begin{array}{l}\text { P512, S516, F517, } \\
\text { Y616, L620, F623, } \\
\text { L624, S785, A786, } \\
\text { L787, N791, V792, } \\
\text { I525(C), S615(C), } \\
\text { N619(C) }\end{array}$ \\
\hline PMP2A & 4 & 1.66 & $\begin{array}{l}\text { N01- } \\
\text { N791:ND2 }\end{array}$ & no $\mathrm{H}$-bonds & $\begin{array}{l}\text { S510, K511, P512, } \\
\text { G513, S516, F517, } \\
\text { D519, P520, Y616, } \\
\text { L620, F623, S788, } \\
\text { N791, I611(D), } \\
\text { S615(D) }\end{array}$ & $\begin{array}{l}\text { F517, D519, P520, } \\
\text { L620, F623, L624, } \\
\text { N791, V792, } \\
\text { S785(B), I611(D), } \\
\text { S615(D) }\end{array}$ \\
\hline PMP2B & 5 & 1.84 & $\begin{array}{l}\text { N01- } \\
\text { S516:OG }\end{array}$ & N01-K511:N & $\begin{array}{l}\text { S510, K511, S516, } \\
\text { F517, D519, P520, } \\
\text { Y616, L620, F623, } \\
\text { S788, N791 }\end{array}$ & $\begin{array}{l}\text { S510, K511, S516, } \\
\text { F517, D519, P520, } \\
\text { Y616, L620, F623, } \\
\text { L624, T784, L787, } \\
\text { N791, V792, S615(A) }\end{array}$ \\
\hline PMP2C & 2 & 0.92 & no $\mathrm{H}$-bonds & $\begin{array}{l}\text { O11- } \\
\text { N791:ND2 }\end{array}$ & $\begin{array}{l}\text { S510, K511, S516, } \\
\text { F517, P520, Y616, } \\
\text { N619, L620, F623, } \\
\text { N791 }\end{array}$ & $\begin{array}{l}\text { K511, S516, F517, } \\
\text { D519, P520, Y616, } \\
\text { N619, L620, F623, } \\
\text { L624, L787, N791, } \\
\text { S615(B), S785(D) }\end{array}$ \\
\hline PMP2D & 3 & 1.81 & $\begin{array}{l}\text { N01- } \\
\text { S516:OG }\end{array}$ & O11-N791:ND2 & $\begin{array}{l}\text { K511, S516, F517, } \\
\text { L518, D519, P520, } \\
\text { Y616, N619, L620, } \\
\text { F623, L624, S788, } \\
\text { N791, S785(A) }\end{array}$ & $\begin{array}{l}\text { S510, K511, P512, } \\
\text { S516, F517, D519, } \\
\text { P520, N619, L620, } \\
\text { F623, N791, V792, } \\
\text { S785(A) }\end{array}$ \\
\hline
\end{tabular}

Table S1. Summary of PMP simulation results. Contacts that persist for more than $60 \%$ of the trajectory are listed. Hydrogen bonds that persisted for less than $20 \%$ of the trajectory are not listed. Hydrogen bonds that persisted for less than $50 \%$ of the trajectory are marked with an asterisk $(*)$. 


\section{Interactions of GYKI with the binding site}

Results of GYKI simulations are summarized in Table S2. Most of the initial contacts of GYKI crystal structure poses are maintained during MD simulations with the exception of GYKID, which shifts in position but remains within the binding pocket (Figure S4). Group 1 poses GYKIA, GYKI1A, GYKI1B, and GYKIC are distinguishable from the rest of the group 1 poses by the presence of a pucker in the diazepine ring of GYKI and the conformation of the side chain of reside F623 with respect to GYKI. Two hydrogen bonds between aminophenyl nitrogen of GYKI and the side chain OH groups of S615 of the neighboring (M3) subunit and Y616 of M3 are formed in most group 1 and group 2 poses. The amide nitrogen of the side chain of N791 also acts as a hydrogen bond donor to either or both ring nitrogens of GYKI in all simulated crystal poses. However, hydrogen bonds to N791 persists for more than $50 \%$ of the of the simulated trajectory only in two out of the four simulated crystal poses (Table S2.) Additionally, one group 2 pose (GYKI2B) forms a weak hydrogen bond with S788. In a majority of both group 1 and group two poses, GYKI form contacts with residues S510, K511, S516, F517, D519, P520, S615 (adjacent subunit), Y616, L620, F623, L624, L877, and N791. Group 2 poses in general interact more strongly with the S2-M4 linker and are more likely to form contacts with residues T784, S785, A786, and S788. Group 1 is more likely to form close contacts with residues S785 or T784 of the S2-M4 linker in the neighboring subunit; GYKIA, GYKIB, GYKI1A, and GYKI1C interact with the S2-M4 linker of the neighboring subunit (see Figure S4). 


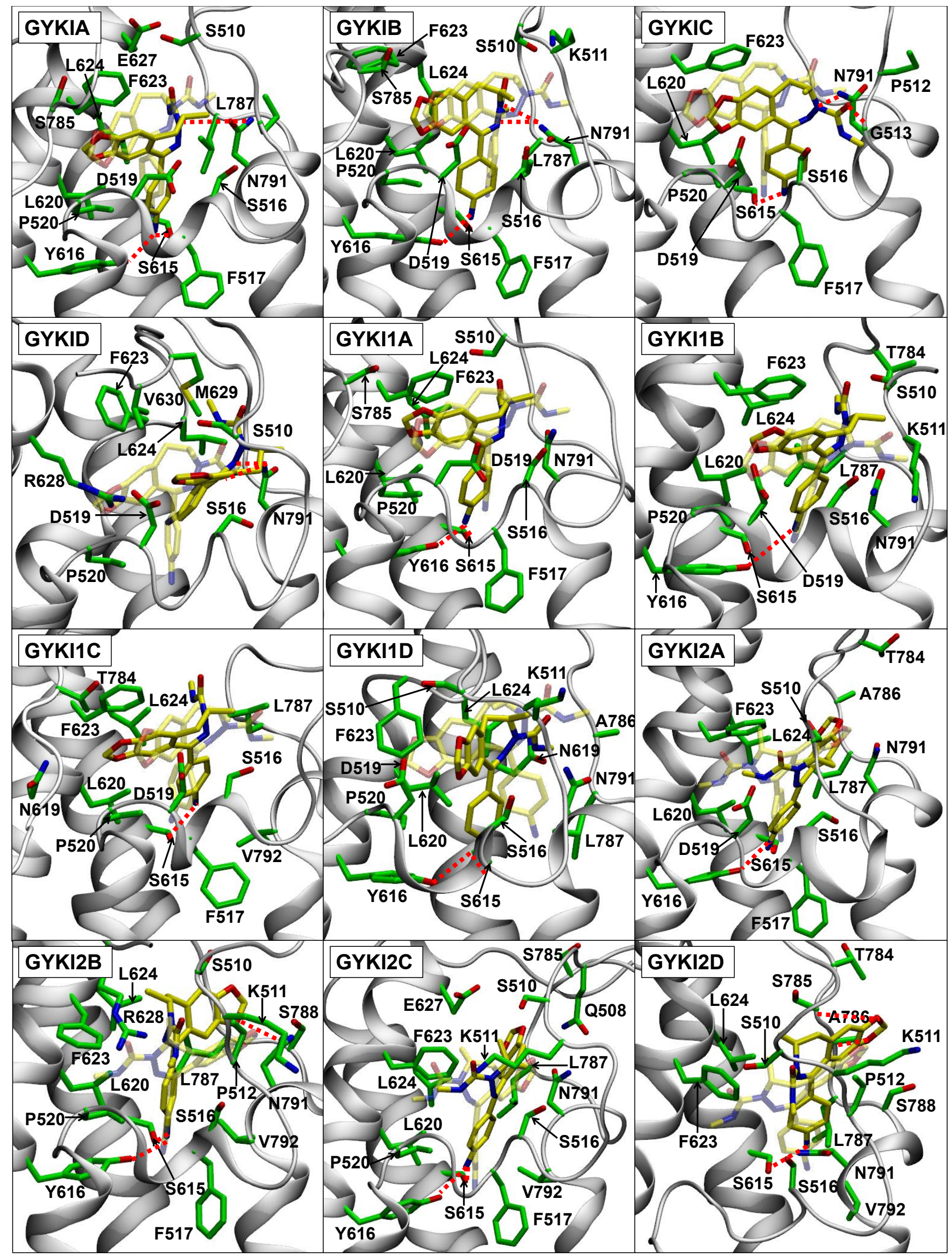


Figure S4. Binding poses of GYKI. Simulated representative structure (opaque) is superimposed on initial ligand position (transparent). All residues within $4 \AA$ of the ligand in the simulated structure are shown. Hydrogen bonds are shown in red dotted lines.

\begin{tabular}{|c|c|c|c|c|c|c|}
\hline $\begin{array}{l}\text { Binding } \\
\text { pose } \\
\text { /bindin } \\
\text { g site }\end{array}$ & $\begin{array}{l}\text { Orientation } \\
\text { (group) }\end{array}$ & $\begin{array}{l}\text { Average } \\
\text { ligand } \\
\text { RMSD/ } \\
\AA\end{array}$ & Initial H-bonds & $\begin{array}{l}\text { H-bonds in } \\
\text { simulated } \\
\text { pose }\end{array}$ & Initial contacts & $\begin{array}{l}\text { Contacts in } \\
\text { simulated pose }\end{array}$ \\
\hline GYKIA & 1 & 2.64 & No H-bonds & $\begin{array}{l}\text { S615(D):OG- } \\
\text { N23, } \\
\text { Y616:OH-N23, } \\
\text { N12- } \\
\text { N791:ND2* }\end{array}$ & $\begin{array}{l}\text { S516, D519, } \\
\text { P520, Y616, } \\
\text { L620, F623, } \\
\text { L624, E627, } \\
\text { N791, S615(D) }\end{array}$ & $\begin{array}{l}\text { S510, P512, } \\
\text { S516, F517, } \\
\text { D519, P520, } \\
\text { Y616, L620, } \\
\text { F623, L624, } \\
\text { E627, L787, } \\
\text { N791, S785(B), } \\
\text { S615(D) }\end{array}$ \\
\hline GYKIB & 1 & 2.70 & O14-S510:OG & $\begin{array}{l}\text { S615(A):OG- } \\
\text { N23*, } \\
\text { Y616:OH-N23, } \\
\text { N12- } \\
\text { N791:ND2, } \\
\text { N02- } \\
\text { N791:ND2 }\end{array}$ & $\begin{array}{l}\text { S510, S516, } \\
\text { D519, P520, } \\
\text { Y616, L620, } \\
\text { F623, L624, } \\
\text { S788, S790, } \\
\text { N791 }\end{array}$ & $\begin{array}{l}\text { S510, K511, } \\
\text { S516, F517, } \\
\text { D519, P520, } \\
\text { Y616, L620, } \\
\text { F623, L624, } \\
\text { L787, N791, } \\
\text { S615(A), S785(C) }\end{array}$ \\
\hline GYKIC & 1 & 3.44 & $\begin{array}{l}\text { S615(B):OG- } \\
\text { N23 }\end{array}$ & $\begin{array}{l}\text { S615(B):OG- } \\
\text { N23, } \\
\text { O14-G513:N, } \\
\text { N12- } \\
\text { N791:ND2* }\end{array}$ & $\begin{array}{l}\text { D519, P520, } \\
\text { L620, F623, } \\
\text { L624, E627, } \\
\text { L787, S788, } \\
\text { N791, S615(B) }\end{array}$ & $\begin{array}{l}\text { P512, G513, } \\
\text { S516, F517, } \\
\text { D519, P520, } \\
\text { L620, F623, } \\
\text { N791, S615(B) }\end{array}$ \\
\hline GYKID & 1 & 3.99 & $\begin{array}{l}\text { S615(C):OG- } \\
\text { N23, } \\
\text { O26- } \\
\text { R628(A):NH2, } \\
\text { O24- } \\
\text { R628(A):NH2 }\end{array}$ & $\begin{array}{l}\text { F613:O-N15*, } \\
\text { N12- } \\
\text { N791:ND2, } \\
\text { N02- } \\
\text { N791:ND2*, }\end{array}$ & $\begin{array}{l}\text { S516, D519, } \\
\text { P520, N619, } \\
\text { L620, F623, } \\
\text { L624, A786, } \\
\text { S788, N791, } \\
\text { R628(A), } \\
\text { S615(C) }\end{array}$ & $\begin{array}{l}\text { S510, S516, } \\
\text { D519, L520, } \\
\text { F623, L624, } \\
\text { M629, V630, } \\
\text { N791, R628(A) }\end{array}$ \\
\hline GYKI1A & 1 & 3.16 & $\begin{array}{l}\text { N791:OD1- } \\
\text { N15, }\end{array}$ & $\begin{array}{l}\text { S615(D):OG:N } \\
23, Y 616: O H- \\
\text { N23, }\end{array}$ & $\begin{array}{l}\text { S510, K511, } \\
\text { P512, S516, } \\
\text { D519, P520, } \\
\text { L620, F623, }\end{array}$ & $\begin{array}{l}\text { S510, S516, } \\
\text { F517, D519, } \\
\text { P520, Y616, } \\
\text { L620, F623, }\end{array}$ \\
\hline
\end{tabular}




\begin{tabular}{|c|c|c|c|c|c|c|}
\hline & & & $\begin{array}{l}\text { N15- } \\
\text { N791:ND2 }\end{array}$ & & $\begin{array}{l}\text { E627, L787, } \\
\text { S788, S790, } \\
\text { N791 }\end{array}$ & $\begin{array}{l}\text { L624, N791, } \\
\text { S785(B), } \\
\text { S615(D) }\end{array}$ \\
\hline GYKI1B & 1 & 3.44 & Y616:OH-N23 & Y616:OH-N23 & $\begin{array}{l}\text { S510, K511, } \\
\text { P512, S516, } \\
\text { F517, D519, } \\
\text { P520, Y616, } \\
\text { L620, F623, } \\
\text { S788, S790, } \\
\text { N791 }\end{array}$ & $\begin{array}{l}\text { S510, K511, } \\
\text { S516, D519, } \\
\text { P520, Y616, } \\
\text { L620, F623, } \\
\text { L624, T784, } \\
\text { L787, N791, } \\
\text { S615(A) }\end{array}$ \\
\hline GYKI1C & 1 & 3.68 & No H-bonds & $\begin{array}{l}\text { S615(B):OG- } \\
\text { N23 }\end{array}$ & $\begin{array}{l}\text { K511, P512, } \\
\text { S516, D519, } \\
\text { P520, L620, } \\
\text { F623, S790, } \\
\text { N791 }\end{array}$ & $\begin{array}{l}\text { S516, F517, } \\
\text { D519, P520, } \\
\text { N619, L620, } \\
\text { F623, L624, } \\
\text { L787, V792, } \\
\text { S615(B), } \\
\text { T784(D) }\end{array}$ \\
\hline GYKI1D & 1 & 3.58 & $\begin{array}{l}\text { O26- } \\
\text { R628(A):NH2, } \\
\text { N23- } \\
\text { N791:ND2 }\end{array}$ & $\begin{array}{l}\text { S615(C):OG- } \\
\text { N23, } \\
\text { Y616:OH-N23 }\end{array}$ & $\begin{array}{l}\text { K511, S516, } \\
\text { D519, P520, } \\
\text { L620, F623, } \\
\text { L624, M629, } \\
\text { L787, S788, } \\
\text { N791, V792, } \\
\text { R628(A) }\end{array}$ & $\begin{array}{l}\text { S510, K511, } \\
\text { S516, D519, } \\
\text { P520, Y616, } \\
\text { L620, F623, } \\
\text { L624, A786, } \\
\text { L787, N791, } \\
\text { S615(C), } \\
\text { N619(C) }\end{array}$ \\
\hline GYKI2A & 2 & 3.09 & O26-S510:OG & $\begin{array}{l}\text { S615(D):OG- } \\
\text { N23, } \\
\text { Y616:OH-N23, }\end{array}$ & $\begin{array}{l}\text { S510, S516, } \\
\text { D519, P520, } \\
\text { L620, F623, } \\
\text { E627, L787, } \\
\text { S788, N791 }\end{array}$ & $\begin{array}{l}\text { S510, S516, } \\
\text { F517, D519, } \\
\text { Y616, L620, } \\
\text { F623, L624, } \\
\text { T784, A786, } \\
\text { L787, N791, } \\
\text { S615(D) }\end{array}$ \\
\hline GYKI2B & 2 & 4.28 & Y616:OH-N23 & $\begin{array}{l}\text { S615(A):OG- } \\
\text { N23, } \\
\text { Y616:OH-N23, } \\
\text { O24-S788:N* }\end{array}$ & $\begin{array}{l}\text { S510, K511, } \\
\text { P512, S516, } \\
\text { F517, D519, } \\
\text { P520, Y616, } \\
\text { L620, F623, } \\
\text { S788, S790, } \\
\text { N791 }\end{array}$ & $\begin{array}{l}\text { S510, K511, } \\
\text { P512, S516, } \\
\text { F517, D519, } \\
\text { Y616, L620, } \\
\text { F623, L624, } \\
\text { R628, L787, } \\
\text { S788, N791, } \\
\text { V792, S615(A) }\end{array}$ \\
\hline
\end{tabular}




\begin{tabular}{|c|c|c|c|c|c|c|}
\hline GYKI2C & 2 & 2.02 & No H-Bonds & $\begin{array}{l}\text { S615(B):OG- } \\
\text { N23, } \\
\text { Y616:OH-N23 }\end{array}$ & $\begin{array}{l}\text { S516, F517, } \\
\text { D519, P520, } \\
\text { Y616, L620, } \\
\text { F623, E627, } \\
\text { A786, L787, } \\
\text { S788, N791 }\end{array}$ & $\begin{array}{l}\text { Q508, S510, } \\
\text { K511, S516, } \\
\text { F517, P520, } \\
\text { Y616, L620, } \\
\text { F623, L624, } \\
\text { E627, S785, } \\
\text { L787, N791, } \\
\text { V792, S615(B) }\end{array}$ \\
\hline GYKI2D & 2 & 3.60 & $\begin{array}{l}\text { O14- } \\
\text { R628(A):NH2 }\end{array}$ & $\begin{array}{l}\text { S615(C):OG- } \\
\text { N23*, } \\
\text { O24-A786:N, } \\
\text { O26-S785 }\end{array}$ & $\begin{array}{l}\text { K511, D519, } \\
\text { P520, L620, } \\
\text { F623, L624, } \\
\text { E627, M629, } \\
\text { A786, L787, } \\
\text { S788, N791, } \\
\text { V792, R628(A), } \\
\text { S615(C) }\end{array}$ & $\begin{array}{l}\text { S510, K511, } \\
\text { P512, S516, } \\
\text { F623, L624, } \\
\text { T784, S785, } \\
\text { A786, L787, } \\
\text { S788, N791, } \\
\text { V792, S615(C) }\end{array}$ \\
\hline
\end{tabular}

Table S2. Summary of GYKI simulation results. Contacts that persist for more than $60 \%$ of the trajectory are listed. Hydrogen bonds that persisted for less than $20 \%$ of the trajectory are not listed. Hydrogen bonds that persisted for less than $50 \%$ of the trajectory are marked with an asterisk (*).

\section{Interactions of $\mathrm{CP}$ with the binding site}

While CP docked more frequently with an orientation similar to the one reported in the crystal structure (group 1), it also produced two other orientations with comparable docking scores (group 2 and 3) (Figure S5.) As with PMP, binding poses of $\mathrm{CP}$ are loosely grouped based on the global orientation of the ligand in the binding pocket. Docking scores and MM-PBSA/GBSA binding energies of CP fall within a wider range compared to PMP and GYKI (see Table S3.) While docking scores do not favor a specific orientation of CP, MM-PBSA/GBSA energies tend to slightly favor group 1 poses. However, CP shows considerable variation in ligand position and contacts formed within a given orientation group. Group 3 consists of only one pose with an orientation that deviates significantly from the X-ray crystal structure pose.

A summary of CP simulation results is shown in Table $\mathbf{S 4}$. On average, CP makes fewer hydrogen bonds with the protein compared to GYKI and PMP. Initial crystal and docked poses only show a few weak hydrogen bonds that are broken quickly during MD simulations. The most prominent hydrogen bond among simulated poses is seen in group 1 poses and involves the carbonyl oxygen of $\mathrm{CP}$ and the $\mathrm{NH}_{2}$ group of $\mathrm{N} 791$. This hydrogen bond is present in three of the simulated crystal structure poses (CPA, CPC, and CPD) as well as two simulated docked poses (CP1A and CP1D) (See Figure S5.) Simulated group 2 poses do not form any persistent hydrogen bonds. However, $\mathrm{CP}$ overall forms more contacts with the protein compared to GYKI and PMP. CP also shows the most variation in contacts formed, including those in initial X-ray crystal structure poses and their simulated states. The main residues that form contacts with most CP binding poses are N791, S510, F517, L620, S516, L624, S615 (adjacent subunit), D519, Y616, L787, V792 and P520. In previous mutagenesis studies, residues D519 and V792 were shown to affect inhibition by $\mathrm{CP}$ [15]. While contact with V792 is not present in initial X-ray crystal poses, it is present in 9 out of 
the 12 simulated poses, including three of the four simulated crystal poses. Residues P512, K511, G627, A786, and S785 and I611 from adjacent subunits also form contacts in some binding poses. CP poses in general tend to interact with the upper part of M3 helix (residues E627, R628, and M629) as well as M3 of the adjacent subunit (residues I611 and N619) more than other ligands. 


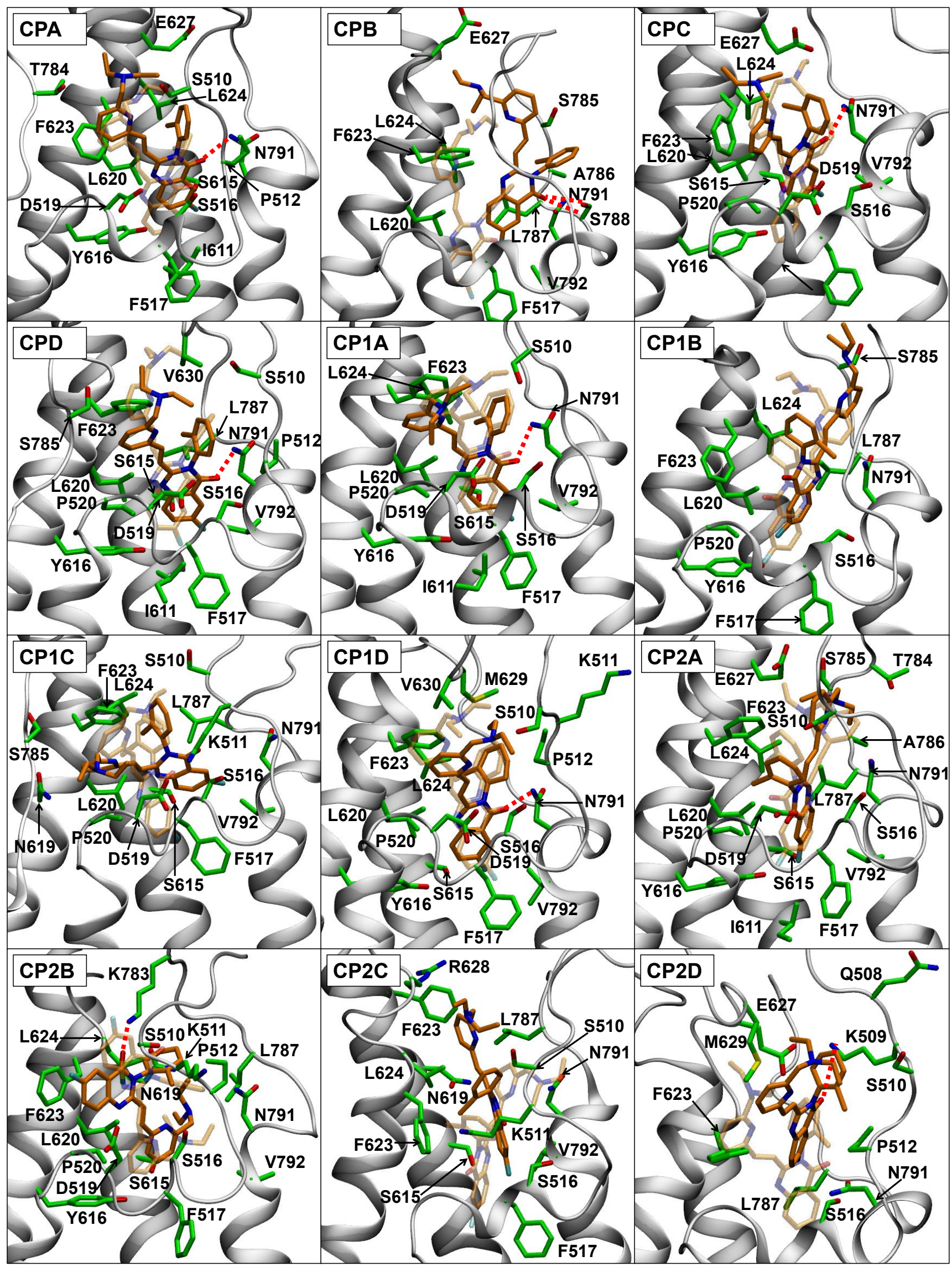


Figure S5. Binding poses of CP. Simulated representative structure (opaque) is superimposed on initial ligand position (transparent). All residues within $4 \AA$ of the ligand in the simulated structure are shown. Hydrogen bonds are shown in red dotted lines.

\begin{tabular}{lll}
\hline Binding pose & Docking score & MM-PBSA \\
\hline Crystal & & \\
CPA & N/A & -27.66 \\
CPB & N/A & -26.35 \\
CPC & N/A & -27.45 \\
CPD & N/A & -34.53 \\
& & \\
Docked & & \\
CP1A & -8 & -31.33 \\
CP1B & -11.4 & -20.82 \\
CP1C & -9.6 & -27.12 \\
CP1D & -6.5 & -31.69 \\
CP2A & -9.2 & -26.1 \\
CP2B & -9 & -30.98 \\
CP2C & -8.9 & -28.22 \\
CP2D & -9.7 & -21.32 \\
\end{tabular}

Table S3. Docking scores and MM-PBSA binding energies of $\mathrm{CP}$ poses. All energies are reported in kcal mol ${ }^{-1}$ 


\begin{tabular}{|c|c|c|c|c|c|c|}
\hline $\begin{array}{l}\text { Binding } \\
\text { pose }\end{array}$ & $\begin{array}{l}\text { Orientation } \\
\text { (group) }\end{array}$ & $\begin{array}{l}\text { Average } \\
\text { ligand } \\
\text { RMSD/ } \\
\AA\end{array}$ & Initial H-bonds & $\begin{array}{l}\text { H-bonds in } \\
\text { simulated } \\
\text { pose }\end{array}$ & Initial contacts & $\begin{array}{l}\text { Contacts in } \\
\text { simulated pose }\end{array}$ \\
\hline CPA & 1 & 3.40 & No H-bonds & $\begin{array}{l}\text { OAA- } \\
\text { N791:ND2 }\end{array}$ & $\begin{array}{l}\text { K509, S516, F517, } \\
\text { D519, P520, } \\
\text { Y616, L620, F623, } \\
\text { E627, L787, } \\
\text { N791, V795, } \\
\text { I611(D) }\end{array}$ & $\begin{array}{l}\text { S510, P512, } \\
\text { S516, F517, } \\
\text { D519, Y616, } \\
\text { L620, F623, } \\
\text { L624, E627, } \\
\text { N791, T784(B), } \\
\text { I611(D), S615(D) }\end{array}$ \\
\hline CPB & 1 & 7.03 & FAF-Y616:OH & $\begin{array}{l}\text { OAA-S788:N, } \\
\text { OAA- } \\
\text { S788:OG* }\end{array}$ & $\begin{array}{l}\text { Q508, S510, } \\
\text { S516, F517, } \\
\text { D519, P520, } \\
\text { Y616, L620, F623, } \\
\text { L624, R628, } \\
\text { N791, V795, } \\
\text { I611(A), R628(C) }\end{array}$ & $\begin{array}{l}\text { F517, L620, } \\
\text { F623, L624, } \\
\text { E627, S785, } \\
\text { A786, L787, } \\
\text { S788, N791, } \\
\text { V792 }\end{array}$ \\
\hline CPC & 1 & 4.36 & NAR-D519:N & $\begin{array}{l}\text { OAA- } \\
\text { N791:ND2 }\end{array}$ & $\begin{array}{l}\text { S516, F517, L518, } \\
\text { D519, P520, } \\
\text { W526, Y616, } \\
\text { L620, F623, L624, } \\
\text { E627, S788, } \\
\text { N791, I611(B) }\end{array}$ & $\begin{array}{l}\text { S516, F517, } \\
\text { D519, P520, } \\
\text { Y616, L620, } \\
\text { F623, L624, } \\
\text { E627, N791, } \\
\text { V792, S615(B) }\end{array}$ \\
\hline CPD & 1 & 4.24 & No H-bonds & $\begin{array}{l}\text { OAA- } \\
\text { N791:ND2 }\end{array}$ & $\begin{array}{l}\text { S516, F517, } \\
\text { D519, P520, } \\
\text { Y616, L620,F623, } \\
\text { L624, E627, } \\
\text { M629, L787, } \\
\text { N791, V795, } \\
\text { R628(A), I611(C) }\end{array}$ & $\begin{array}{l}\text { S510, P512, } \\
\text { S516, F517, } \\
\text { D519, P520, } \\
\text { Y616, L620, } \\
\text { F623, V630, } \\
\text { L787, N791, } \\
\text { V792, S785(A), } \\
\text { I611(C), S615(C) }\end{array}$ \\
\hline CP1A & 1 & 1.24 & No H-bonds & $\begin{array}{l}\text { OAA- } \\
\text { N791:ND2 }\end{array}$ & $\begin{array}{l}\text { K509, K511, S516, } \\
\text { F517, D519, } \\
\text { P520, Y66, L620, } \\
\text { F623, L624, E627, } \\
\text { N791 }\end{array}$ & $\begin{array}{l}\text { S510, S516, } \\
\text { F517, D519, } \\
\text { P520, Y616, } \\
\text { L620, F623, } \\
\text { L624, N791, } \\
\text { V792, I611(D), } \\
\text { S615(D) }\end{array}$ \\
\hline
\end{tabular}




\begin{tabular}{|c|c|c|c|c|c|c|}
\hline CP1B & 2 & 2.46 & No H-bonds & $\begin{array}{l}\text { OAA- } \\
\text { K511NZ* }\end{array}$ & $\begin{array}{l}\text { S510, S516, F517, } \\
\text { D519, P520, } \\
\text { Y616, L620, F623, } \\
\text { L624, V626, E627, } \\
\text { S785, A786, L787, } \\
\text { S788, N791 }\end{array}$ & $\begin{array}{l}\text { S516, F517, } \\
\text { P520, Y616, } \\
\text { L620, F623, } \\
\text { L624, S785, } \\
\text { L787, N791 }\end{array}$ \\
\hline CP1C & 1 & 2.02 & No H-bonds & $\begin{array}{l}\text { No persistent } \\
\text { H-bonds }\end{array}$ & $\begin{array}{l}\text { S516, F517, } \\
\text { D519, P520, } \\
\text { Y616, L620, F623, } \\
\text { L624, E627, N791 }\end{array}$ & $\begin{array}{l}\text { S510, K511, } \\
\text { S516, F517, } \\
\text { D519, P520, } \\
\text { N619, L620, } \\
\text { F623, L624, } \\
\text { L787, N791, } \\
\text { V792, S615(B), } \\
\text { S785(D) }\end{array}$ \\
\hline CP1D & 1 & 1.25 & No H-bonds & $\begin{array}{l}\text { OAA- } \\
\text { N791:ND2 }\end{array}$ & $\begin{array}{l}\text { K509, S516, F517, } \\
\text { D519, P520, } \\
\text { Y616, L620, F623, } \\
\text { L624, M629, } \\
\text { N791, V795, } \\
\text { S615(A) }\end{array}$ & $\begin{array}{l}\text { S510, K511, } \\
\text { P512, S516, } \\
\text { F517, D519, } \\
\text { P520, Y616, } \\
\text { L620, F623, } \\
\text { L624, M629, } \\
\text { V630, N791, } \\
\text { V792, S615(C) }\end{array}$ \\
\hline CP2A & 2 & 2.62 & No H-bonds & $\begin{array}{l}\text { No persistent } \\
\text { H-bonds }\end{array}$ & $\begin{array}{l}\text { S510, S516, F517, } \\
\text { P520, Y616, F623, } \\
\text { L624, E627, R628, } \\
\text { A786, L787, } \\
\text { N791, N619(D) }\end{array}$ & $\begin{array}{l}\text { S510, S516, } \\
\text { F517, D519, } \\
\text { P520, Y616, } \\
\text { L620, F623, } \\
\text { L624, E627, } \\
\text { T784, S785, } \\
\text { A786, L787, } \\
\text { N791, V792, } \\
\text { I611(D), S615(D) }\end{array}$ \\
\hline CP2B & 3 & 3.25 & FAF-Q508:NE2 & $\begin{array}{l}\text { OAA- } \\
\text { K783:NZ* }\end{array}$ & $\begin{array}{l}\text { Q508, S510, } \\
\text { K511, S516, F517, } \\
\text { D519, P520, } \\
\text { Y616, L620, F623, } \\
\text { L624, R628, L787, } \\
\text { S788, N791, } \\
\text { V792, S615(A), } \\
\text { R628(C) }\end{array}$ & $\begin{array}{l}\text { S510, K511, } \\
\text { P512, S516, } \\
\text { F517, D519, } \\
\text { P520, Y616, } \\
\text { L620, F623, } \\
\text { L624, K783, } \\
\text { L787, N791, } \\
\text { V792, S615(A), } \\
\text { N619(A) }\end{array}$ \\
\hline CP2C & 2 & 5.11 & No H-bonds & $\begin{array}{l}\text { No persistent } \\
\text { H-bonds }\end{array}$ & $\begin{array}{l}\text { Q508, K511, } \\
\text { P512, S516, F517, } \\
\text { P520, Y616, L620, }\end{array}$ & $\begin{array}{l}\text { S510, K511, } \\
\text { S561, F517, } \\
\text { F623, L624, }\end{array}$ \\
\hline
\end{tabular}




\begin{tabular}{|c|c|c|c|c|c|c|}
\hline & & & & & $\begin{array}{l}\text { F623, L624, E627, } \\
\text { A786, L787, S788, } \\
\text { S790, N791 }\end{array}$ & $\begin{array}{l}\text { R628, L787, } \\
\text { N791, V792, } \\
\text { S615(B), } \\
\text { N619(B), F623(B) }\end{array}$ \\
\hline CP2D & 1 & 6.22 & FAF-N791:ND2 & $\begin{array}{l}\text { OAA- } \\
\text { K509:NZ* }\end{array}$ & $\begin{array}{l}\text { K509, K511, } \\
\text { P512, S516, } \\
\text { D519, L620, F623, } \\
\text { L624, R628, } \\
\text { M629, V630, } \\
\text { L787, S788, N791, } \\
\text { V792, R628(A), } \\
\text { S785(A) }\end{array}$ & $\begin{array}{l}\text { Q508, K509, } \\
\text { S510, P512, } \\
\text { S516, F623, } \\
\text { E627, M629, } \\
\text { L787, N791 }\end{array}$ \\
\hline
\end{tabular}

Table S4. Summary of CP simulation results. Contacts that persist for more than $60 \%$ of the trajectory are listed. Hydrogen bonds that persisted for less than $20 \%$ of the trajectory are not listed. Hydrogen bonds that persisted for less than $50 \%$ of the trajectory are marked with an asterisk (*). 

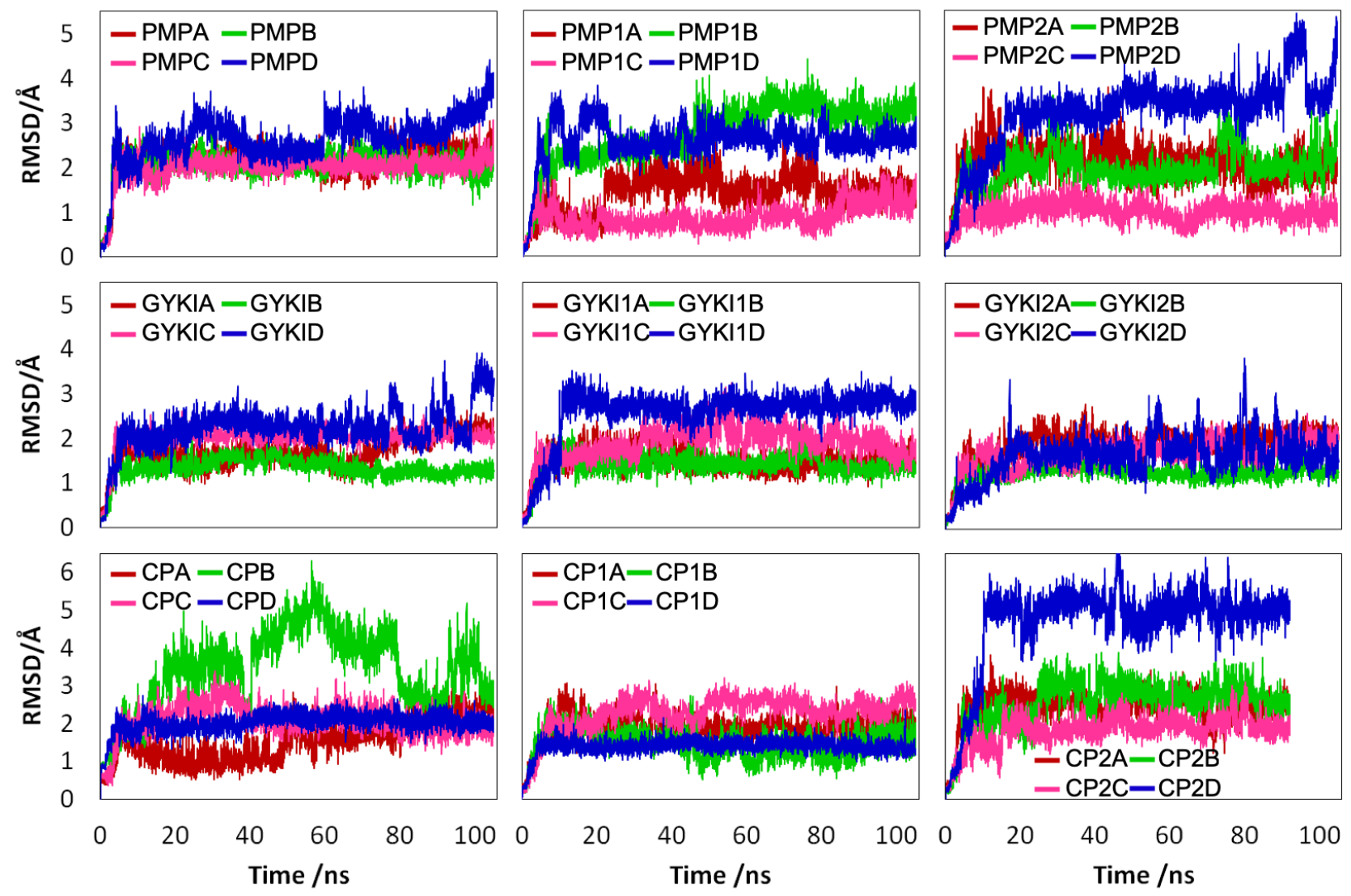

Figure S6: Ligand "RMSD" based on selected ligand-protein residue distances with respect to initial ligand position. Each plot shows a single simulation with four bound ligands. Trajectory analysis was performed on time periods 50-75 ns for GYKI and CP, and 35-60 ns for PMP. 

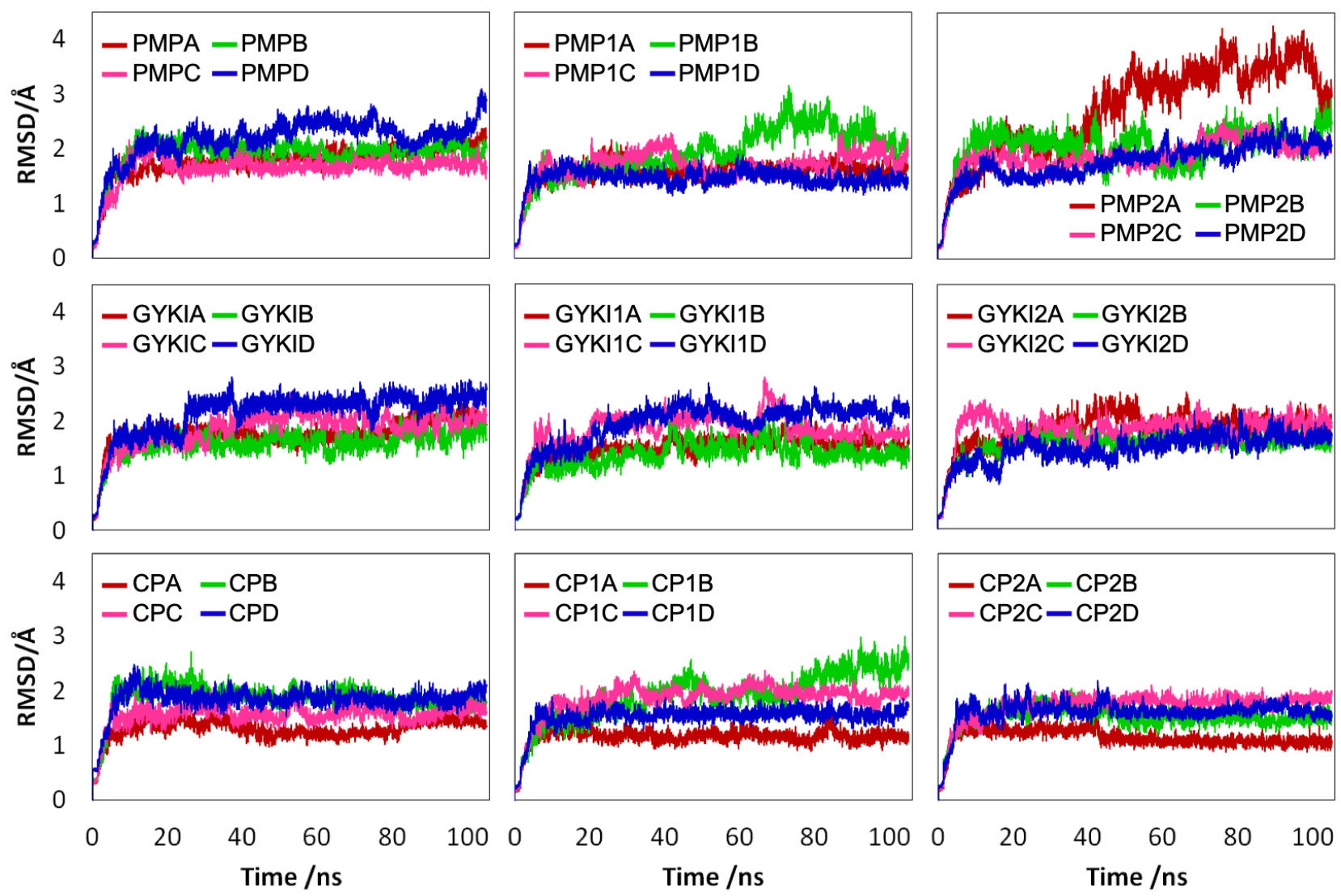

Figure S7: RMSD of the binding site - residues 511-523 (pre-M1/S1-M1 linker), 615-629 (M3), and 786-795 (M4/S2-M4 linker) - with respect to initial structure. Trajectory analysis was performed on time periods 50-75 ns for GYKI and CP, and 35-60 ns for PMP. 


\section{Correlation between TI and MM-PBSA free energies}
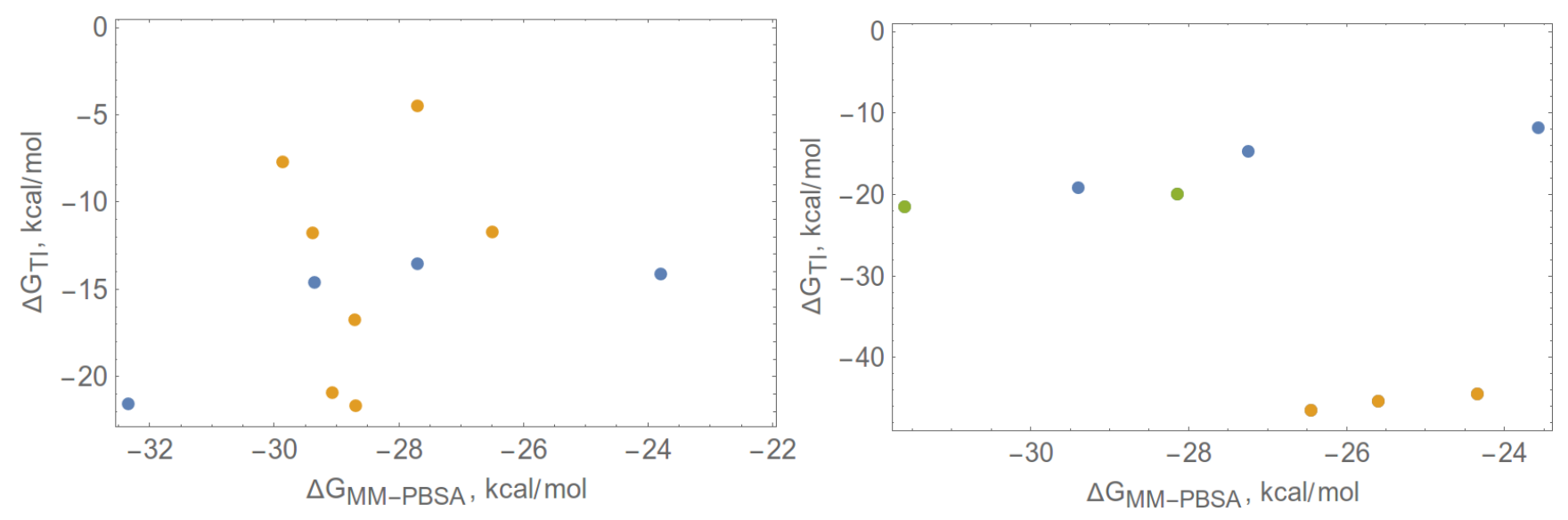

Figure S8. Correlation between TI and MM-PBSA free energies. A) PMP. Blue colored dots represent energies of crystal-like (group 1) poses, yellow represent the energies of flipped (group 2) poses. B) GYKI. Green dots represent free energies of the "flipped" poses, yellow and blue colored dots represent energies of crystal-like poses. Yellow dots represent puckered GYKI poses. 
6. M3-S2 linker in diagonal subunits

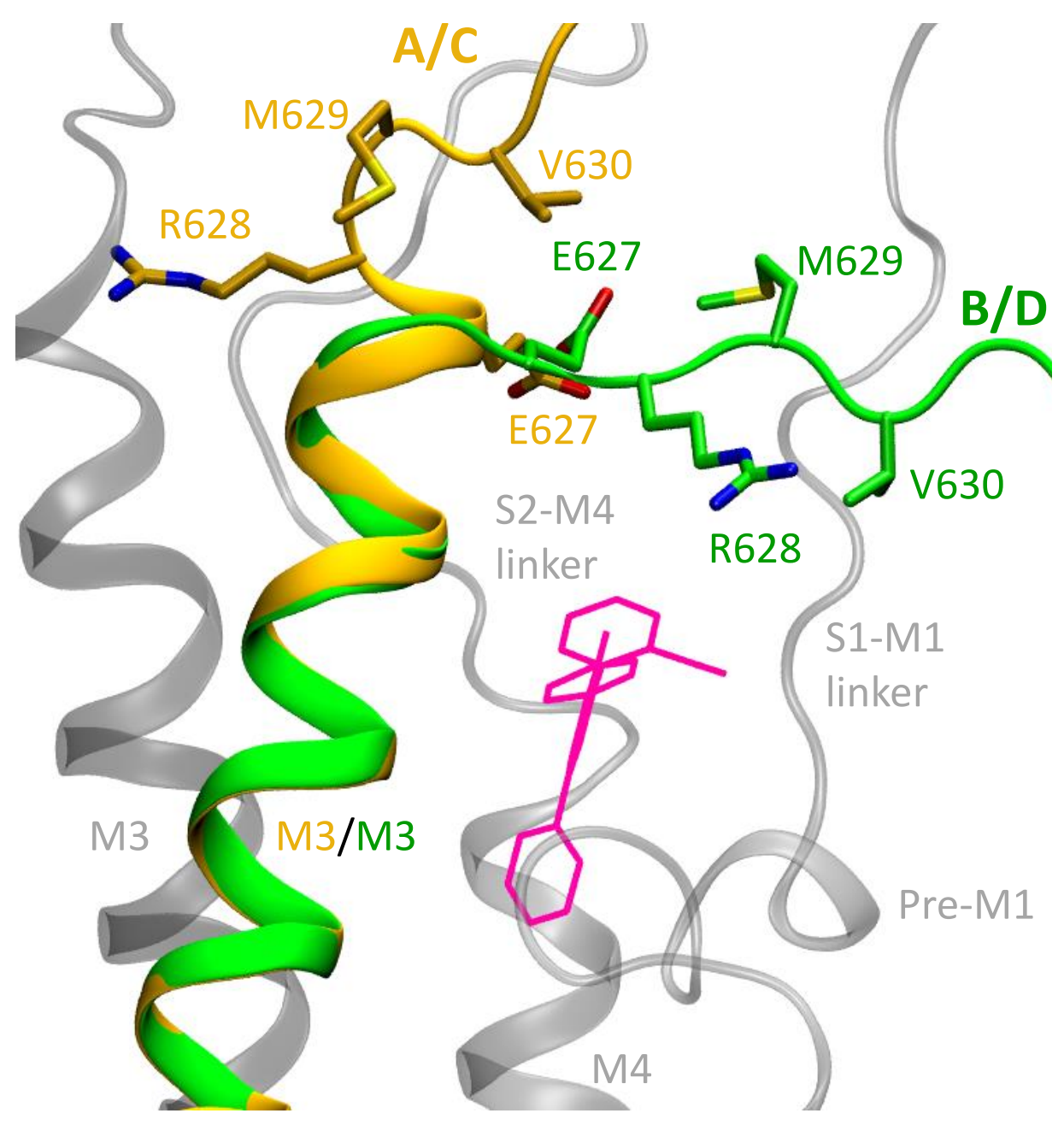

Figure S9. Different conformations adopted by M3-S2 linker in diagonal subunits A/C (yellow) and B/D (green). Residues in M3-S2 linker that form interactions with inhibitors are labeled. 


\section{Chemical structures of Inhibitors}
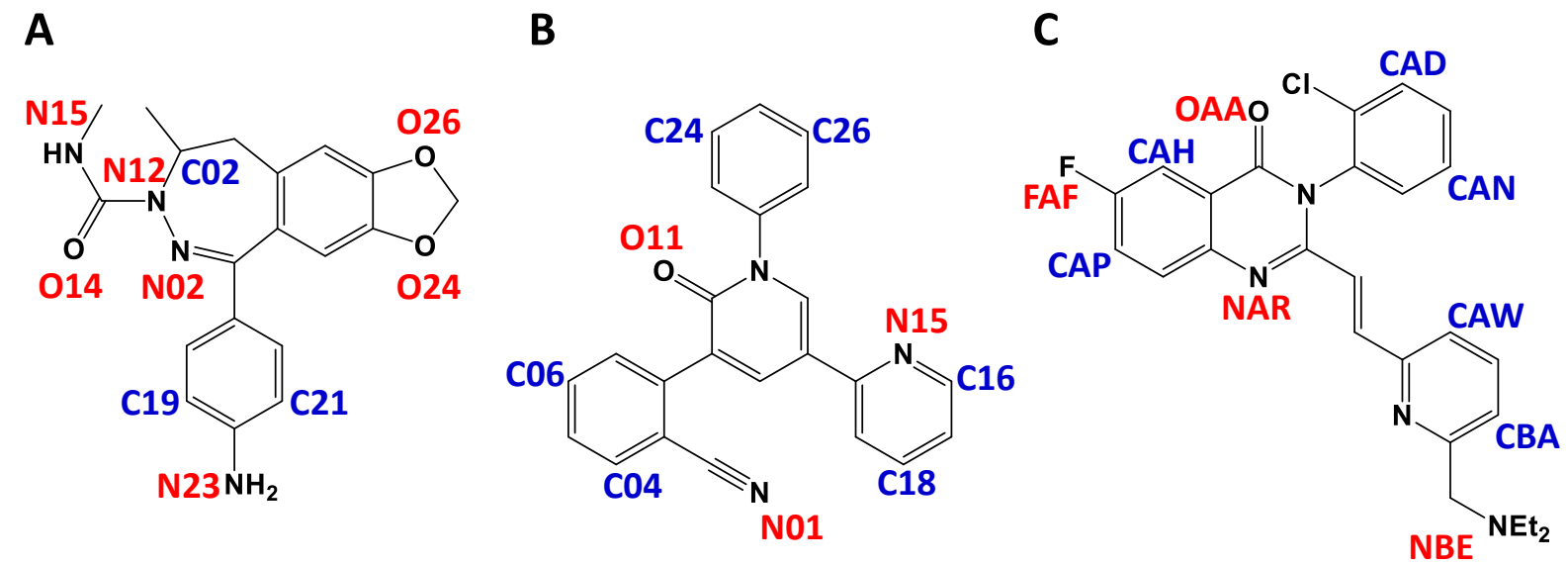

Figure S10. Chemical structures of A) GYKI, B) PMP, and C) CP. Hydrogen bonding groups (red) and additional ligand atoms used in RMSD calculations (blue) are labeled. Atoms labels are the same as in PDBs 5L1H, 5L1F, and 5L1E.

\section{SUPPLEMENTAL METHODS}

\section{General protocol for MD simulations}

MD simulations of truncated TMD systems

The general protocol used for MD simulations is as follows. First, minimization was carried out in two stages; a) lipids and waters were minimized for 50000 steps keeping the protein and ligands fixed. b) the system was minimized for 20000 steps keeping protein C- $\alpha$ atoms and ligand heavy atoms fixed. Each minimization stage consisted of equal numbers of steepest descent and conjugate gradient steps. The system was slowly heated from $0.1 \mathrm{~K}$ to $300 \mathrm{~K}$ using NPT ensemble in five stages over 250 ps with protein heavy atoms and all ligand atoms restrained with a force constant of $20 \mathrm{kcal} \mathrm{mol}^{-1} \AA^{-2}$. The system was then equilibrated using NPT ensemble for a total of $12 \mathrm{~ns}$, slowly releasing the restraints on protein and ligands. The harmonic restraints on the protein-ligand complex and the length of each NPT step are as follows; a) All ligand atoms and protein heavy atoms were restrained using a force constant of $20 \mathrm{kcal}$ $\mathrm{mol}^{-1} \AA^{-2}$ for $1 \mathrm{~ns}$. b) All ligand atoms and protein heavy atoms were restrained using a force constant of $10 \mathrm{kcal} \mathrm{mol}^{-1} \AA^{-2}$ for $1 \mathrm{~ns}$. c) All ligand atoms and protein heavy atoms were restrained using a force constant of $5 \mathrm{kcal} \mathrm{mol}^{-1} \AA^{-2}$ for $1 \mathrm{~ns}$. d) Protein $\mathrm{C}-\alpha \mathrm{s}$ and ligand heavy atoms were restrained using a force constant of $5 \mathrm{kcal} \mathrm{mol}^{-1} \AA^{-2}$ for $1 \mathrm{~ns}$. e) Protein $\mathrm{C}-\alpha$ s and ligand heavy atoms were restrained using a force 
constant of $3 \mathrm{kcal} \mathrm{mol}^{-1} \AA^{-2}$ for $1 \mathrm{~ns}$. f) Protein $\mathrm{C}-\alpha \mathrm{s}$ and ligand heavy atoms were restrained using a force constant of $2 \mathrm{kcal} \mathrm{mol}^{-1} \AA^{-2}$ for $1 \mathrm{~ns}$. g) Protein $\mathrm{C}-\alpha \mathrm{s}$ and ligand heavy atoms were restrained using a force constant of $1 \mathrm{kcal} \mathrm{mol}^{-1} \AA^{-2}$ for $1 \mathrm{~ns}$. h) Protein $\mathrm{C}-\alpha$ s and the central aromatic ring of the ligands were restrained using a force constant of $1 \mathrm{kcal} \mathrm{mol}^{-1} \AA^{-2}$ for $1 \mathrm{~ns}$. i) Protein $\mathrm{C}-\alpha \mathrm{s}$ and the central aromatic ring of the ligands were restrained using a force constant of $0.5 \mathrm{kcal} \mathrm{mol}^{-1} \AA^{-2}$ for $2 \mathrm{~ns}$. j) Protein C- $\alpha$ s and the central aromatic ring of the ligands were restrained using a force constant of $0.2 \mathrm{kcal} \mathrm{mol}^{-1} \AA^{-2}$ for $1 \mathrm{~ns} . \mathrm{k}$ ) Protein $\mathrm{C}-\alpha$ s and the central aromatic ring of the ligands were restrained using a force constant of $0.1 \mathrm{kcal}$ $\mathrm{mol}^{-1} \AA^{-2}$ for $1 \mathrm{~ns}$. Equilibration was followed by a production run of $100 \mathrm{~ns}$ in NPT ensemble. The end residues of the TMD-LBD linkers (residues 506 and 782) were weakly restrained using a force constant of $0.1 \mathrm{kcal} \mathrm{mol}^{-1} \AA^{-2}$ throughout all simulations. All other restraints were removed for the production run.

MD simulations of TMD-LBD system

The protocol for equilibration of the TMD-LBD system was the same as the truncated TMD simulation protocol with the following changes to heating and equilibration steps. The system was heated from 0.1 $\mathrm{K}$ to $100 \mathrm{~K}$ over $50 \mathrm{ps}$ in NVT ensemble and from $100 \mathrm{~K}$ to $300 \mathrm{~K}$ in four 50 ps steps in NPT ensemble. Equilibration was carried out over $55 \mathrm{~ns}$, replacing each step (a-k) in the truncated TMD simulation protocol with a $5 \mathrm{~ns}$ step. The harmonic restraints on protein and ligand atoms were the same for both systems in each equilibration step. All restraints on the TMD-LBD system were removed for the production run of $800 \mathrm{~ns}$.

\section{Calculation of ligand "RMSD"}

Ligand "RMSD" reported is the root mean square deviation of protein-ligand atom pair distances listed in Table S11. Atom names listed are the same as in PDBs 5L1H, 5L1F, and 5L1E. For each pose, twelve protein-ligand atom pairs between six protein residues in different parts of the binding site identified to contribute to inhibitor binding in previous mutagenesis studies and six ligand atoms in peripheral rings of the inhibitor in close proximity to the selected receptor atoms in the initial crystal or docked structure were used. Distances used to calculate ligand RMSD for group 1 PMP poses are shown in Figure S11.

\begin{tabular}{|l|l|}
\hline Binding Poses & Atom pairs \\
\hline PMP group 1 & S788:CB-C04, S788:CB-C06, N791:CB-C04, N791:CB-C06, \\
(PMPA-D, & F517:CB-C16, F517:CB-C18, S615:CB-C16, S615:CB-C18, \\
PMP1B, PMP1D) & P520:CA-C24, P520:CA-C26, F623:CB-C24, F623:CB-C26 \\
\hline
\end{tabular}




\begin{tabular}{|c|c|}
\hline $\begin{array}{l}\text { PMP group } 2 \\
\text { (PMP1A, } \\
\text { PMP2C) }\end{array}$ & $\begin{array}{l}\text { S788:CB-C24, S788:CB-C26, N791:CB-C24, N791:CB-C26, } \\
\text { F517:CB-C04, F517:CB-C06, S615:CB-C04, S615:CB-C06, } \\
\text { P520:CA-C16, P520:CA-C18, F623:CB-C16, F623:CB-C18 }\end{array}$ \\
\hline $\begin{array}{l}\text { PMP group } 3 \\
\text { (PMP1C, } \\
\text { PMP2C) }\end{array}$ & $\begin{array}{l}\text { S788:CB-C04, S788:CB-C06, N791:CB-C04, N791:CB-C06, } \\
\text { F517:CB-C24, F517:CB-C26, S615:CB-C24, S615:CB-C26, } \\
\text { P520:CA-C16, P520:CA-C18, F623:CB-C16, F623:CB-C18 }\end{array}$ \\
\hline $\begin{array}{l}\text { PMP group } 4 \\
\text { (PMP2A) }\end{array}$ & $\begin{array}{l}\text { S788:CB-C16, S788:CB-C18, N791:CB-C16, N791:CB-C18, } \\
\text { F517:CB-C04, F517:CB-C06, S615:CB-C04, S615:CB-C06, } \\
\text { P520:CA-C24, P520:CA-C26, F623:CB-C24, F623:CB-C26 }\end{array}$ \\
\hline $\begin{array}{l}\text { PMP group } 5 \\
\text { (PMP2B) }\end{array}$ & $\begin{array}{l}\text { S788:CB-C16, S788:CB-C18, N791:CB-C16, N791:CB-C18, } \\
\text { F517:CB-C24, F517:CB-C26, S615:CB-C24, S615:CB-C26, } \\
\text { P520:CA-C04, P520:CA-C06, F623:CB-C04, F623:CB-C06 }\end{array}$ \\
\hline $\begin{array}{l}\text { GYKI group } 1 \\
\text { (GYKIA-D, } \\
\text { GYKI1A-D) }\end{array}$ & $\begin{array}{l}\text { S788:CB-N11, S788:CB-C02, N791:CB-N11, N791:CB-C02, } \\
\text { F517:CB-C19, F517:CB-C21, S615:CB-C19, S615:CB-C21, } \\
\text { P520:CA-O24, P520:CA-O26, F623:CB-O24, F623:CB-O26 }\end{array}$ \\
\hline $\begin{array}{l}\text { GYKI group } 2 \\
\text { (GYKI2A-D) }\end{array}$ & $\begin{array}{l}\text { S788:CB-O24, S788:CB-O26, N791:CB-O24, N791:CB-O26, } \\
\text { F517:CB-C19, F517:CB-C21, S615:CB-C19, S615:CB-C21, } \\
\text { P520:CA-N11, P520:CA-C02, F623:CB-N11, F623:CB-C02 }\end{array}$ \\
\hline $\begin{array}{l}\text { CP group } 1 \\
\text { (CPA-D, CP1A, } \\
\text { CP1C-D, CP2D) }\end{array}$ & $\begin{array}{l}\text { S788:CB-CAN, S788:CB-CAD, N791:CB-CAN, N791:CB-CAD, } \\
\text { F517:CB-CAH, F517:CB-CAP, S615:CB-CAH, S615:CB-CAP, } \\
\text { P520:CA-CAW, P520:CA-CBA, F623:CB-CAW, F623:CB-CBA }\end{array}$ \\
\hline $\begin{array}{l}\text { CP group } 2 \\
(\mathrm{CP} 1 \mathrm{~B}, \mathrm{CP} 2 \mathrm{~A} \\
\mathrm{CP} 2 \mathrm{C})\end{array}$ & $\begin{array}{l}\text { S788:CB-CAW, S788:CB-CBA, N791:CB-CAW, N791:CB-CBA, } \\
\text { F517:CB-CAH, F517:CB-CAP, S615:CB-CAH, S615:CB-CAP, } \\
\text { P520:CA-CAN, P520:CA-CAD, F623:CB-CAN, F623:CB-CAD }\end{array}$ \\
\hline $\begin{array}{l}\text { CP group } 3 \\
(\mathrm{CP} 2 \mathrm{~B})\end{array}$ & $\begin{array}{l}\text { S788:CB-CAN, S788:CB-CAD, N791:CB-CAN, N791:CB-CAD, } \\
\text { F517:CB-CAW, F517:CB-CBA, S615:CB-CAW, S615:CB-CBA, } \\
\text { P520:CA-CAH, P520:CA-CAP, F623:CB-CAH, F623:CB-CAP }\end{array}$ \\
\hline
\end{tabular}

Table S11. Protein-ligand atom pair distances used to calculate ligand RMSD. 


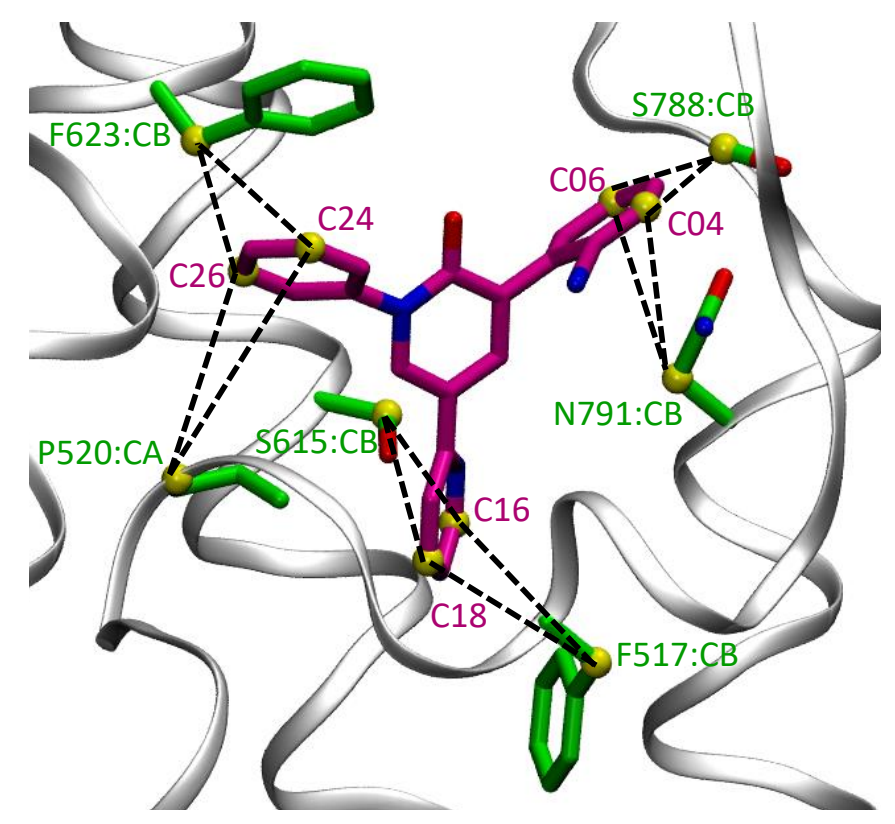

Figure S11. Protein-ligand atom pair distances used to calculate ligand RMSD for group 1 PMP poses. 